\title{
Pathophysiological Mechanisms Underlying the Efficacy and Safety of Sublingual Immunotherapy
}

\author{
Cristoforo Incorvaia ${ }^{1^{*}}$, Luciano Loperfido ${ }^{1}$ and Gualtiero Leo ${ }^{2}$ \\ ${ }^{1}$ Allergy/Pulmonary Rehabilitation, ASST Gaetano Pini/CTO, Milan, Italy \\ ${ }^{2}$ Pediatric Allergy and Respiratory Pathophysiology Unit, Vittore Buzzi Children's Hospital, ASST Fatebenefratelli Sacco, Milan, Italy
}

"Corresponding author: Cristoforo Incorvaia, Allergy/Cardiac and Pulmonary Rehabilitation, ASST Gaetano Pini/CTO, Via Bignami, 20126 Milan, Italy, Tel: +390257993289; E-mail: cristoforo.incorvaia@gmail.com

Received date: April 16, 2016; Accepted date: April 18, 2016; Published date: April 22, 2016

Copyright: (c) 2016 Incorvaia C, et al. This is an open-access article distributed under the terms of the Creative Commons Attribution License, which permits unrestricted use, distribution, and reproduction in any medium, provided the original author and source are credited.

\begin{abstract}
The results of meta-analyses show that sublingual immunotherapy (SLIT) is as efficacious as subcutaneous immunotherapy (SCIT) and more safe in treating patients with allergic rhinitis. In both issues, immunity of the oral mucosa, that is more oriented to tolerance to antigens than respiratory mucosa or skin, plays a pivotal role. In particular, the immunological organs contained in the Waldeyer ring, that is, adenoids, tubal tonsil, palatine tonsil and lingual tonsil are currently investigated concerning their specific function in the response to the allergens administered by SLIT. These studies have the prospective to improve the understanding of immunity of the oral mucosa and to refine the techniques to deliver SLIT.
\end{abstract}

Keywords: Sublingual immunotherapy; Efficacy; Safety; Immunity of the oral mucosa; Waldeyer ring

\section{Editorial}

Sublingual immunotherapy (SLIT) is an efficacious treatment of allergic rhinitis, as clearly demonstrated by meta-analyses [1-3], based on its capacity to work on the causes of allergy and not only on symptoms, as drugs make instead $[4,5]$. This outcome is related to the mechanisms of action of allergen immunotherapy, that appear to be similar for SLIT and the traditional, subcutaneous immunotherapy (SCIT) and mainly consist in the generation of $\mathrm{T}$ regulatory cells favoring tolerance to the administered allergen's and the shifting from the Th2 cytokine profile (typical of allergy) to the Th1 profile [6]. However, some diversities are apparent between the two routes of administration, that are likely to be due to the different pathophysiology of the skin and the oral mucosa. For example, the safety of SLIT is better than SCIT, the most common reactions occurring locally in the mouth, while systemic reactions are rare and anaphylactic reactions extremely rare $[7,8]$. Such good safety profile allows to administer by the sublingual route allergen doses much higher (up to hundreds of time) than those injected by SCIT. Also, the high safety of SLIT permitted to perform the treatment in patients allergic to house dust mites by a schedule alternating two months of SLIT and two months of interruption, with re-start of the treatment without repeating the build-up phase [9]. Of course, such schedule is not feasible for SCIT, because of the risk of systemic reactions.

The background for this kind of approach is provided by studies investigating the pathophysiology of the oral mucosa. A cell type particularly involved in allergic reaction is the mast cell, due to its capacity to rapidly release mediators such as histamine and leukotrienes as well as inflammatory cytokines [10]. In a study assessing by biopsies the cellular changes occurring in local oral reactions to SLIT, a low number of mast cells was found in subepidermal level in perivascular sites, some with surface IgE, with no significant differences in biopsies before and after the administration of the allergen extract [11]. This suggests that events other than mediators release by mast cells are involved in local reactions to SLIT. As far as the mechanisms underlying the efficacy of SLIT are concerned, in recent years the role of the set of immunological organs defined as Waldeyer ring, that has the function of producing antibodies toward the common environmental antigens and includes adenoids, tubal tonsil, palatine tonsil, and lingual tonsil, was also investigated. Palomares et al. suggested that human tonsils may be potential first-line organs of oral tolerance induction by producing allergen-specific FOXP3+ Treg cells [12]. Focusing the interest on SLIT, it has been reported that performing a polymerase chain reaction (PCR) array on mRNA extracted in adenoid samples from allergic children treated by SLIT, a reduced expression of IL-4, CCR2, CCR3, and PTGDR2 (Th2 related genes) and CD28, IL-2, and INHA (Th1 related genes) was found [13]. Ongoing studies are investigating the particular role of lingual tonsil. In bovines, immunohistochemical analysis suggested that the lingual tonsil can be considered as an inductive site, sampling and processing antigens to stimulate naïve $\mathrm{T}$ and B lymphocytes. Since this tonsil can be located macroscopically by the openings of its follicular crypts at the root of tongue, its localization in bovines was described as a prerequisite for the removal of specified risk material from the tongue meat to prevent the risk of bovine spongiform encephalopathy [14]. Concerning humans, preliminary findings indicate that materials sublingually administered to sensitized subjects, containing the specific allergen or inert substances, are rapidly driven to the lingual tonsil, that is apparently an initial sampling site from where the different destination of antigens is programmed [15].

Indeed, the disposition of the immunological organs in the oral mucosa to favour tolerance is easily understandable if one considers that all foods pass through the mouth and the occurrence in the oral mucosa of the same defensive attitude of the immunological organs in the respiratory tracts or in the skin would make feeding impossible. However, the specific role of the single components of the Waldeyer ring is far from clear. The current research line on this issue could pave the way to studies aimed at improving the understanding of immunity 
Citation: Incorvaia C, Loperfido L, Leo G (2016) Pathophysiological Mechanisms Underlying the Efficacy and Safety of Sublingual Immunotherapy. J Allergy Ther 7: e113. doi:10.4172/2155-6121.1000e113

Page 2 of 2

of the oral mucosa and refining the administration techniques to perform SLIT.

\section{References}

1. Wilson DR, Lima MT, Durham SR (2005) Sublingual immunotherapy for allergic rhinitis: systematic review and meta-analysis. See comment in PubMed Commons below Allergy 60: 4-12.

2. Radulovic S, Wilson D, Calderon M, Durham S (2011) Systematic reviews of sublingual immunotherapy (SLIT). See comment in PubMed Commons below Allergy 66: 740-752.

3. Devillier P, Dreyfus JF, Demoly P, Calderón MA (2014) A meta-analysis of sublingual allergen immunotherapy and pharmacotherapy in polleninduced seasonal allergic rhinoconjunctivitis. See comment in PubMed Commons below BMC Med 12: 71.

4. Scadding G, Durham S (2009) Mechanisms of sublingual immunotherapy. See comment in PubMed Commons below J Asthma 46 322-334.

5. Incorvaia C, Moingeon P, Buttafava S, Frati F (2015) Focusing the mechanism of action to dissect the different treatments of respiratory allergy. See comment in PubMed Commons below Expert Rev Clin Immunol 11: 1005-1013.

6. Cavkaytar O, Akdis CA, Akdis M (2014) Modulation of immune responses by immunotherapy in allergic diseases. See comment in PubMed Commons below Curr Opin Pharmacol 17: 30-37.

7. Senna G, Caminati M, Canonica GW (2013) Safety and tolerability of sublingual immunotherapy in clinical trials and real life. See comment in PubMed Commons below Curr Opin Allergy Clin Immunol 13: 656-662.

8. Frati F, Ridolo E, Fuiano N, Barberi S, Dell'Albani I, et al. (2014) Safety of sublingual immunotherapy in children. See comment in PubMed Commons below Expert Opin Drug Saf 13: 947-953.
9. Cadario G, Ciprandi G, Di Cara G, Fadel R, Incorvaia C, et al. (2008) Comparison between continuous or intermittent schedules of sublingual immunotherapy for house dust mites: effects on compliance, patients satisfaction, quality of life and safety. See comment in PubMed Commons below Int J Immunopathol Pharmacol 21: 471-473.

10. Siraganian RP (2003) Mast cell signal transduction from the high-affinity IgE receptor. See comment in PubMed Commons below Curr Opin Immunol 15: 639-646.

11. Marcucci F, Sensi L, Incorvaia C, Di Cara G, Moingeon P, et al. (2007) Oral reactions to sublingual immunotherapy: a bioptic study. See comment in PubMed Commons below Allergy 62: 1475-1477.

12. Palomares O, Rückert B, Jartti T, Kücüksezer UC, Puhakka T, et al. (2012) Induction and maintenance of allergen-specific FOXP3+ Treg cells in human tonsils as potential first-line organs of oral tolerance. See comment in PubMed Commons below J Allergy Clin Immunol 129: 510-520, 520 .

13. Masieri S, Trabattoni D, Incorvaia C, De Luca MC, Dell'Albani I, et al (2014) A role for Waldeyer's ring in immunological response to allergens. See comment in PubMed Commons below Curr Med Res Opin 30: 203-205.

14. Cocquyt G, Simoens P, Muylle S, Van den Broeck W (2008) Anatomical and histological aspects of the bovine lingual tonsil. See comment in PubMed Commons below Res Vet Sci 84: 166-173.

15. Frati F, Masieri S, Incorvaia C, Buttafava S, Mascarell L, et al. (2016) Is lingual tonsil a preferential target for processing sublingually administered substances? Allergy Asthma Proc. 